Brazilian Journal

of Chemical

\title{
KINETICS OF THE BIODEGRADATION OF MONOAROMATICS BY Pseudomonas aeruginosa
}

\author{
Jéssica M. D. A. Câmara ${ }^{1 *}$, M. A. S. B. Sousa ${ }^{1}$ and E. L. B. Neto ${ }^{1}$ \\ ${ }^{1}$ Universidade Federal do Rio Grande do Norte, Departamento de Engenharia Química, Natal/RN, Brasil. E-mail: jessica_damiao@ufrn.edu.br, \\ ORCID: 0000-0001-6066-7606
}

(Submitted: May 31, 2017 ; Revised: February 4, 2018 ; Accepted: February 6, 2018)

\begin{abstract}
Water contamination by monoaromatic compounds has risen throughout time, which leads to the necessity of developing new water treatment technology, capable of minimizing their negative effect on the environment. In this context, biological processes present themselves as a solution to the processes of extraction. Bioremediation makes use of microbial groups capable of using hydrocarbons as a source of carbon to perform their metabolic functions. This work evaluated the biodegradation efficiency of Pseudomonas aeruginosa strain isolated from contaminated matrices, for the substrates benzene, ethylbenzene and toluene, aiming to determine to which compound the bacteria had better adaptation. For that, bioremediation assays were performed for each of the monoaromatic compounds, in an isolated way, with the goal of obtaining experimental data and from this Monod and Andrews kinetic models were discretized and numerically developed through the Runge-Kutta method. It was possible to observe that Pseudomonas aeruginosa has a bigger affinity for ethylbenzene, while benzene generated a bigger microbian coefficient. Monod's model was capable of predicting satisfactorily the experimental data.

Keywords: Water treatment; Monoaromatic compounds; Pseudomonas aeruginosa; Bioremediation; Biological processes.
\end{abstract}

\section{INTRODUCTION}

Monoaromatic compounds, such as benzene, toluene and ethylbenzene, which have their chemical structures shown in Figure 1, represent an important class of pollutant due to their high toxic potential to

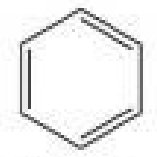

Benzene<smiles>Cc1ccccc1</smiles>

Methylbenzene (toluene)

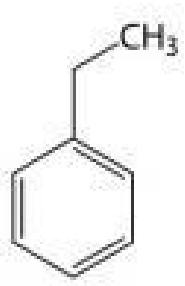

Ethylbenzene
Figure 1. Monoaromatic compounds chemical structure (Benzene, toluene and ethylbenzene). different organisms (Anneser et al., 2008) (JO et al., 2008). They are found in oil derivatives and are widely used in chemical industries as raw-materials for the synthesis of other products (Phelps and Young, 2001).

Environmental pollution caused by petroleum hydrocarbons represents a great risk to ecosystems (Mousa et al., 2014). In a specific way, monoaromatic compounds present an elevated solubility in water, which facilitates the migration and fast contamination of underground water and soil by these compounds that, even in low concentrations, may cause serious harm to the environment and to human health (Aivalioti et al., 2012) (Mazzeo et al., 2010) (Jo et al., 2008) (Santaella et al., 2009) (Paixâo et al., 2007).

The high mobility of these hydrocarbons in soilwater systems is related to their low coefficient of partition octanol-water, which gives the soil a low absorption potential, and, consequently, a preferred

\footnotetext{
*Corresponding author: Jéssica M. D. A Câmara - E-mail: jessica_damiao@ufrn.edu.br
} 
transport through water. This fact favors the contamination of water reservoirs (Nakhla, 2003).

As the contamination of underground water by hydrocarbons has been growing (REUSSER et al., 2002) there is the necessity of developing more efficient methods to remove or minimize the damage caused by these compounds (Mazzeo et al., 2010).

However, normally, the conventional physicalchemical treatments used to remove monoaromatic compounds from the environment, besides demanding high operational costs, do not destroy the contaminants, only phase transport them. In that sense, biological processes are considered an efficient technology, especially because of their operational simplicity and low cost when compared to other methods (Moussa et al., 2014) (Bertin et al., 2007) (Massalha et al., 2007) (Mazzeo et al., 2010).

Bioremediation consists of using microbian groups capable of degrading hydrocarbons. These microorganisms are able to biotransform pollutant molecules into nutrients for the realization of their metabolic and physiologic functions. The biological degradation processes (biodegradation) of the organic compounds are made through the breaking of these compound into less toxic substances, such as $\mathrm{CO}_{2}$, water and methane (Bittkau et al., 2004) (Farhadian et al., 2009) (Martínez et al., 2007).

Degradations of aromatic compounds using bacteria of the Pseudomonas gender are commonly mentioned, such as Pseudomonas putida (Ridgway et al., 1990; Lee et al., 1994; Otenio et al., 2005; Shim et al., 2005; Lin et al., 2010); Pseudomonas aeruginosa (Ridgway et al., 1990; Nwinyi et al., 2016; Chebbi et al., 2017; Khodaei et al., 2017); Pseudomonas fluorescens (Ridgway et al., 1990; Shim et al., 2005; Oberoi and Philip, 2017); Pseudomonas aureofaciens (Dou et al. 2008); Pseudomonas stutzeri (Singh and Tiwary, 2017); Pseudomonas plecoglossicida (Li et al., 2017).

This work used as microorganism Pseudomonas aeruginosa, a Gram-negative bacterium, which can be isolated from different habitats including water, the soil and the plants, and under specific environmental conditions. Besides that, it is able to produce a biosurfactant containing the glycolipid ramnose. The type and the proportion of the rhamnolipid produced depends on the strain, of the carbon source used and of the cultivation conditions (Santa Anna et al., 2002; Fontes et al., 2008). Joined to this capability, Pseudomonas aeruginosa consumes monoaromatic compounds, using them as a source of carbon and energy, besides presenting high growth rates under high substract concentrations (Malhautier et al., 2014).

The knowledge of the biodegradation kinetics of these pollutants and their adjustment to a model is indispensable for the project of adequate treatment systems on a real scale. Therefore, this study aims to investigate and model the biodegradation of the monoaromatic compounds benzene, toluene and ethylbenzene in water and the evaluation of their consumption by the bacteria Pseudomonas aeruginosa over time, using a greater compound concentration range than the one commonly used in previous studies.

\section{METHODS}

\section{Pseudomonas aeruginosa}

A bacterial strain of Pseudomonas aeruginosa was selected from a soil that was artificially contaminated with a solution of diesel oil of $2.50 \mathrm{~g} / 1$ and moisturized with the mineral medium described by Robert et al. (1989), in order to provide all the nutrients needed for the development of the microorganism. This strain was isolated and selected through inoculation in Acetamide Agar qualitative medium and Cetrimide Agar quantitative medium, which are both selective media for Pseudomonas aeruginosa.

After a $\mathrm{pH}$ adjustment to 7.0, the cultivation medium was sterilized at $121^{\circ} \mathrm{C}$ and 1 atm during 15 minutes. As a pre-inoculum, a nutrient solution of peptone, $2 \%$ in mass, was used, which remained in the shaker at $200 \mathrm{rpm}$ agitation and at $30{ }^{\circ} \mathrm{C}$ for 10 hours (Miguez et al., 2012).

\section{Bioremediation essays}

In the bioremediation assays $50 \mathrm{~mL}$ of the medium described by Robert et al. (1989) was used, in erlenmeyers of $125 \mathrm{~mL}$, inoculated with $1 \mathrm{~mL}$ of the pre-inoculum (cellular suspension of Pseudomonas aeruginosa) and contaminated synthetically from a concentrated solution of benzene, ethylbenzene or toluene in initial concentrations of $200 \mathrm{mg} / \mathrm{L}, 150$ $\mathrm{mg} / \mathrm{L}$ and $170 \mathrm{mg} / \mathrm{L}$, respectively, that were defined from the solubility of them in the water medium.

The erlenmeyers were accommodated in a shaking table, at 28 degrees Celsius and $200 \mathrm{rpm}$, kept for 3 hours, with samples taken each 15 minutes, for celular growth e substrate consumption analysis.

\section{Analytical measurements}

The cellular concentration was determined through the dry mass. Therefore, samples of the fermented medium were filtered through a previously weighed membrane, followed by system introduction (membrane+cells) into an incubator at $105^{\circ} \mathrm{C}$. After 2 hours of drying, the membrane was put in a desiccator with silica gel until cooled and, just then the membrane with the dry cellular mass was weighed. The mass determination was made by the difference of the final and initial weight of the membranes. The membranes used for the execution of this analysis were the membranes for ultra-filtering of pore diameter of 0.45 $\mu \mathrm{m}$ and brand MILLIPORE® (Vitolo et al., 1995). 
The determination of the substrate consumption was made by liquid chromatography. Therefore, a C18 HPLC column of $15 \mathrm{cms}$ length and $4.6 \mathrm{~mm}$ of internal diameter was utilized, with a solution of $70 \%$ of acetronitrile and $30 \%$ of water in volume, in a flow of $1 \mathrm{~mL} / \mathrm{min}$, and injecting 50 microliters of the sample. Prior to sample reading a standard curve was made for each compound, using a range from $10 \mathrm{mg} / \mathrm{L}$ up to the maximum solubility in water concentration.

\section{Modeling}

The modeling of the biodegradation of these compounds enables the study of the influences of the process parameters on the biomass growth and substrate consumption, besides the formation of products, being important for the comprehension of microbian biology, as well as internal control mechanisms (Trigueros et al., 2010).

The Monod model (Equation 1) is applied to study the kinetics of the biodegradation of a single substrate. In it, the parameters are the specific growth rate $\left(\mu_{\max }\right)$ and the Monod $\left(\mathrm{K}_{\mathrm{S}}\right)$ saturation constant, which represents the value of concentration of the substrate $\mathrm{S}$, at which the specific growth rate is equal to half of its maximum value, and indicates especially the affinity of the microorganism and the substrate.

Monod considers that all the components of the culture medium, with the exception of the substrate (monoaromatic compounds), are present in high concentrations, in such a way as changes in these conditions do not affect significantly the cellular growth rate (Bailey and Ollis, 1986).

$\mu_{\mathrm{x}}=\mu_{\max } \frac{\mathrm{S}(\mathrm{t})}{\mathrm{K}_{\mathrm{S}}+\mathrm{S}(\mathrm{t})}$

The Andrews model (Equation 2) considers the substrate limitation through the inhibition constant $\mathrm{K}_{\mathrm{I}}$, that, if too big indicates that the bioprocess inhibition does not occur because of the substrate presence. If $\mathrm{K}_{\mathrm{I}}>>\mathrm{S}$, the Andrews model becomes the Monod model.

$$
\mu_{x}=\mu_{\max } \frac{\mathrm{S}(\mathrm{t})}{\mathrm{K}_{\mathrm{S}}+\mathrm{S}(\mathrm{t})+\frac{\mathrm{S}(\mathrm{t})^{2}}{\mathrm{~K}_{\mathrm{I}}}}
$$

This kinetic model was incorporated into the mass balance for each substrate and biomass in a bioreactor operating in the batch mode (Equations 3 and 4, respectively) where $\mathrm{Yx} / \mathrm{s}$ corresponds to the substrate tax that is transformed into biomass.

$$
\frac{\mathrm{dS}(\mathrm{t})}{\mathrm{dt}}=-\frac{\mu_{\mathrm{x}}}{\mathrm{Y}_{\mathrm{x} / \mathrm{s}}} \cdot \mathrm{X}(\mathrm{t})
$$

$$
\frac{\mathrm{dX}(\mathrm{t})}{\mathrm{dt}}=\mu_{\mathrm{x}} \cdot \mathrm{X}(\mathrm{t})
$$

The differential equations mentioned were discretized and the tangent function was adjusted through the Runge-Kutta $4^{\text {th }}$ order method. The evaluation of the model efficiency was made through the minimum value of the objective function (F. O.), given by the minimum squares. To the variables substrate $(S)$ biomass $(X)$, the calculus of the objective function is given by the Equations 5 and 6, respectively.

$$
\begin{aligned}
& \text { F.O. }=\sum_{i}\left(\frac{S_{i}^{\text {cal }}}{S^{\max }}-\frac{S_{i}}{S_{\text {max }}}\right)^{2} \\
& \text { F.O. }=\sum_{i}\left(\frac{X_{i}^{\text {cal }}}{X^{\text {max }}}-\frac{X_{i}}{X_{\text {max }}}\right)^{2}
\end{aligned}
$$

For each substrate the relative error sum $\left(\mathrm{e}_{\mathrm{m}}\right)$ of all the points was calculated using Equation 7 , that represents the difference between the sum of the experimental values (X) and the values obtained through the model $\left(\mathrm{X}_{\mathrm{i}}^{\mathrm{cal}}\right)$, over the experimental values.

$$
\mathrm{e}_{\mathrm{m}}=\frac{\sum_{\mathrm{i}}^{\mathrm{n}}\left(\frac{\mathrm{X}_{\mathrm{i}}-\mathrm{X}_{\mathrm{i}}^{\text {cal }}}{X_{\mathrm{i}}}\right)}{\mathrm{n}}+\frac{\sum_{\mathrm{i}}^{\mathrm{n}}\left(\frac{\mathrm{S}_{\mathrm{i}}-\mathrm{S}_{\mathrm{i}}^{\text {cal }}}{\mathrm{S}_{\mathrm{i}}}\right)}{\mathrm{n}}
$$

\section{RESULTS AND DISCUSSION}

The results of the consumption of toluene, ethylbenzene and benzene are presented in Figures 2, 3 and 4, respectively. After 2 hours, for most initial concentrations that have been studied, the

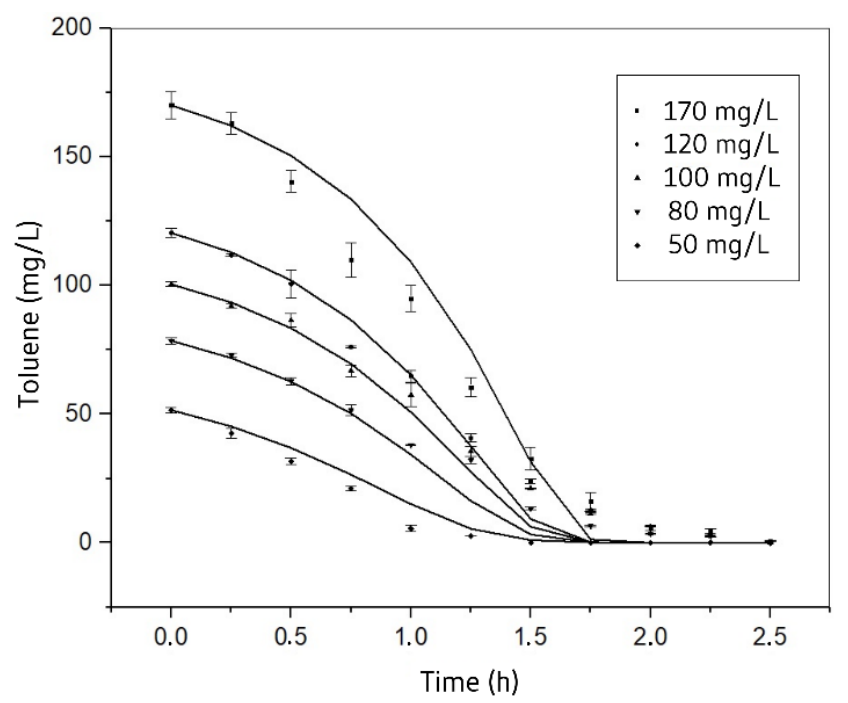

Figure 2. Experimental (symbol) and calculated data (lines) of toluene consumption with time. 


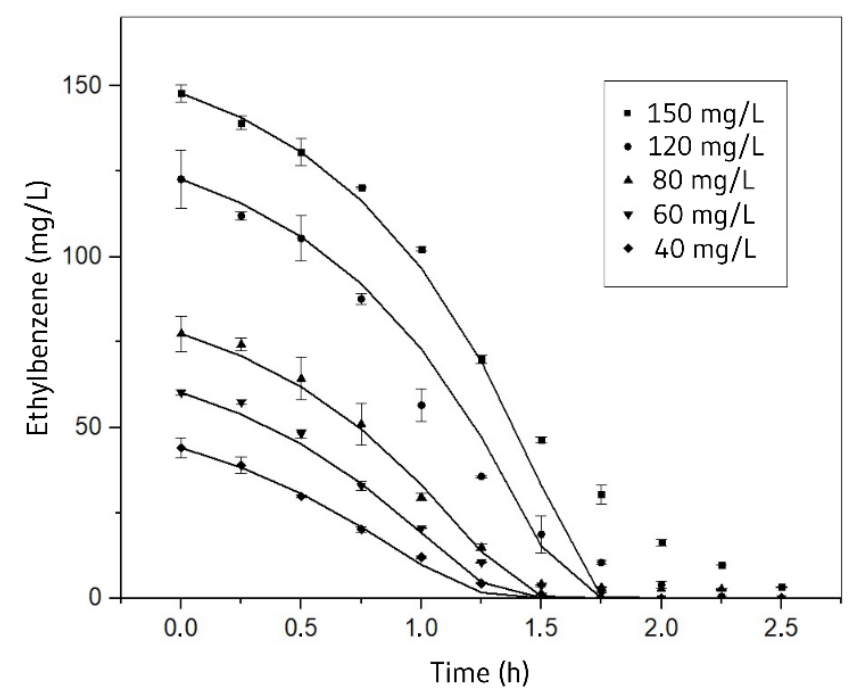

Figure 3. Experimental (symbol) and calculated data (lines) of ethylbenzene consumption with time.

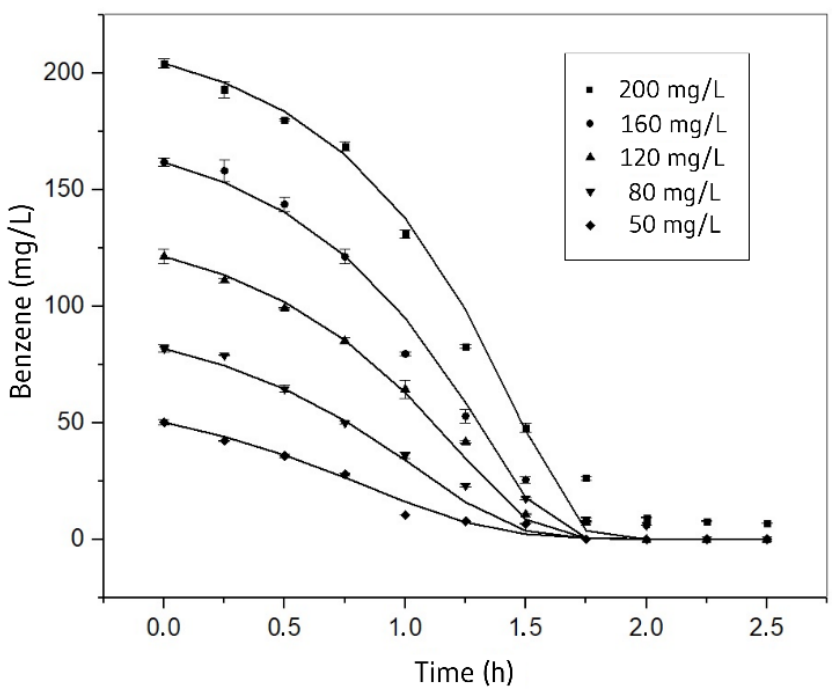

Figure 4. Experimental (symbol) and calculated data (lines) of benzene consumption with time.

concentrations of toluene, ethylbenzene, and benzene reached zero and the biodegradation yield reached $100 \%$ after 2.5 hours of test. These values are more expressive than previous studies with other microorganisms., that obtained yields near $80 \%$ with a kinetic time varying from 6 to 48 hours (Khodaei et al., 2017; Nagarajan and Loh, 2014; Drakou et al., 2015; El-Naas et al., 2014 Morlett-Chávez et al., 2010; Parameswapara et al., 2008).

The biomass growth curves for toluene, ethylbenzene and benzene are presented in Figures 5, 6 e 7 respectively, where it was possible to verify that none presented a lag phase of growth, which shows that a period of adaptation to the substrate was not necessary. This can be proved plotting the curve of $\ln X$ versus time, which indicated the beginning of the exponential phase of growth during the first instants of cultivation. It was also possible to observe that,

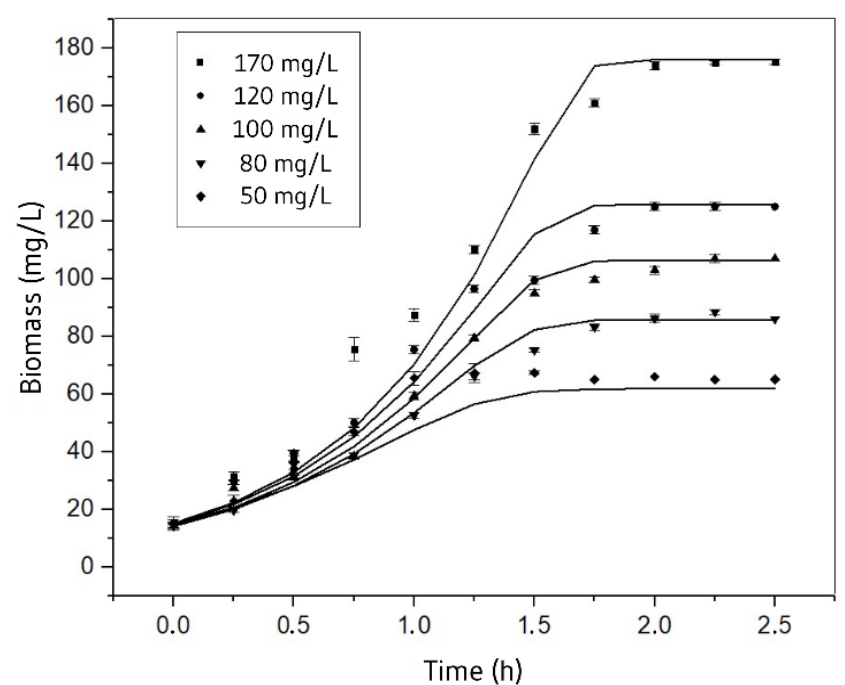

Figure 5. Experimental (symbol) and calculated data (lines) biomass growth for toluene.

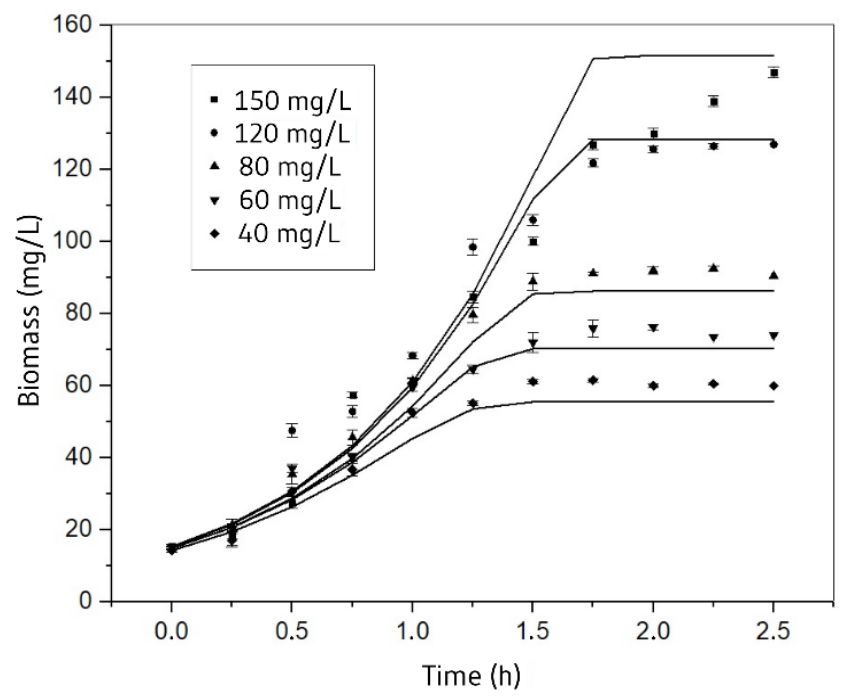

Figure 6. Experimental (symbol) and calculated data (lines) biomass growth for ethylbenzene.

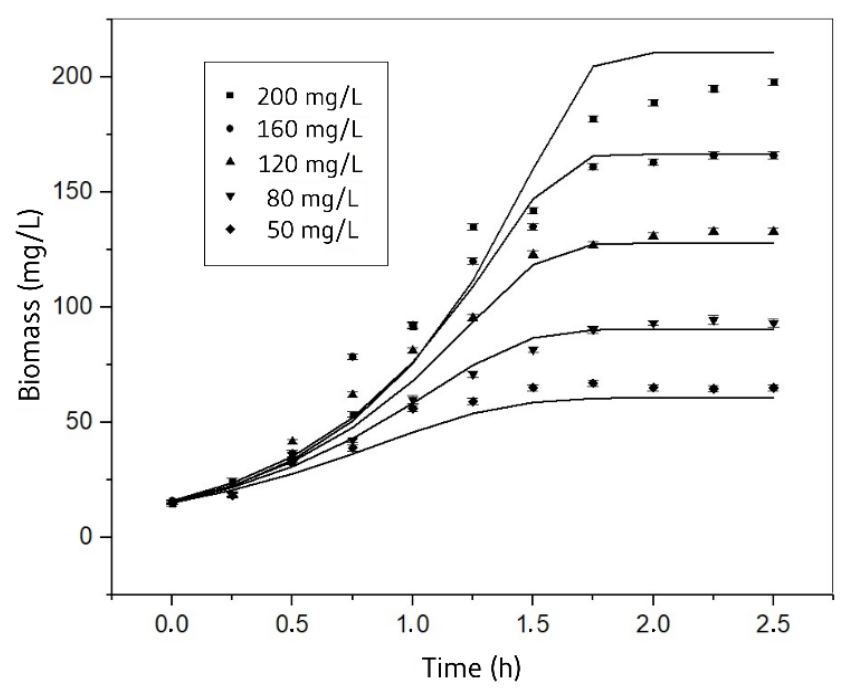

Figure 7. Experimental (symbol) and calculated data (lines) biomass growth the benzene. 
with carbon availability reduction, a reduction in the growth rate of Pseudomonas aeruginosa also occurred as shown in other studies (Drakou et al., 2015; Malhautier et al., 2014).

The modeling of the experimental data which refer to the biomass generation and substrate consumption curves of toluene, ethylbenzene and benzene made from the differential equations 3 and 4 corresponds to the solid curves of Figures 2 to 7 . The kinetic behavior of the three substrates is consistent with the Monod model with an average error varying between 0.194 to 0.465 , while there was no adjustment to the Andrews model, showing that the chemical biodegradation of the studied monoaromatics does not suffer inhibition from the substrate. The parameter values of the Monod model for each one of the substrates are presented in Table 1, including the values of the average errors of the Monod model for each monoaromatic.

The value of $\mu_{\max }$ is compatible with other studies made for different types of Pseudomonas. For toluene, they obtained $0.053 \mathrm{~h}^{-1}$ with a mixed microbial consortium (Rajamanickam et al., 2017), $0.17 \mathrm{~h}^{-1}$ for Pseudomonas putita (Mathur and Majumder, 2010), $0.42 \mathrm{~h}^{-1}$ for Pseudomonas putita 54g (Mirpuri et al., 1997), $1.56 \mathrm{~h}^{-1}$ for Pseudomonas putita OI (Oh et al., 1994) and $0.78 \mathrm{~h}^{-1}$ for Pseudomonas putita F1 (Bordel et al., 2007). As for benzene: $0.1613 \mathrm{~h}^{-1}$ for Pseudomonas putita (MA/athur and Majumder, 2010), $0.5 \mathrm{~h}^{-1}$ for Pseudomonas putida F1 (Robledo-Ortíz et al., 2011) and $0.75 \mathrm{~h}^{-1}$ for Pseudomonas putida F1 (Abuhamed et al., 2004).

The maximum specific growth rate obtained for each monoaromatic showed a tendency of reduction upon substitution of the aromatic ring with the alkyl group, with the bigger chain of the substituent group, the lower the rate. This result is consistent with those obtained from the kinetics of toluene in contrast with benzene with Pseudomonas putida (Mathur and Majumder, 2010) and Pseudomonas putida F1 (Abuhamed et al., 2004).

The saturation constant $(K s)$, which is defined as the substrate concentration in which $\mu_{x}$ is equal to half of $\mu_{\max }$ also presented values on the same order of magnitude of those presented in the literature. For toluene, $62.56 \mathrm{mg} / \mathrm{L}$ was obtained for Pseudomonas putita (Mathur and Majumder, 2010), $3.98 \mathrm{mg} / \mathrm{L}$ for Pseudomonas putita 54G (Mirpuri et al., 1997), 15.07 $\mathrm{mg} / \mathrm{L}$ for Pseudomonas putita OI (Oh et al., 1994) and $5.00 \mathrm{mg} / \mathrm{L}$ for Pseudomonas putita F1 (Bordel et al.,

Table 1. Kinetic parameters.

\begin{tabular}{lccc}
\hline \multirow{2}{*}{ Parameter } & \multicolumn{3}{c}{ Compound } \\
\cline { 2 - 4 } & Benzene & Toluene & Ethylbenzene \\
\hline$\mu_{\text {máx }}\left(\mathrm{h}^{-1}\right)$ & 1.86 & 1.72 & 1.48 \\
$\mathrm{~K}_{\mathrm{s}}(\mathrm{mg} / \mathrm{L})$ & 22.67 & 16.53 & 7.53 \\
$\mathrm{Y}_{\mathrm{x} / \mathrm{s}}(\mathrm{mg} / \mathrm{mg})$ & 0.848 & 0.849 & 0.851 \\
$\mathrm{e}_{\mathrm{m}}$ & 0.364 & 0.194 & 0.465 \\
\hline
\end{tabular}

2007). As for benzene: $71.18 \mathrm{mg} / \mathrm{L}$ for Pseudomonas putita (Mathur and Majumder, 2010), $10.11 \mathrm{mg} / \mathrm{L}$ for Pseudomonas putida F1 (Robledo-Ortíz et al., 2011) and $1.65 \mathrm{mg} / \mathrm{L}$ for Pseudomonas putida F1 (Aabuhamed et al., 2004).

The lowest Ks value was obtained for ethylbenzene, indicating that the microorganism presents a bigger compatibility with this compound. This can be explained by the fact that groups in the aromatic ring affect its reactivity. The presence of alkyl groups activates the ring, making it more reactive and easier to break. The bigger the alkyl group chain is, the more electrical density is donated and more reactive is the aromatic ring, which explains the increased compatibility of ethylbenzene in relation to the other compounds that were studied. These results are consistent with the ones obtained through other studies (Littlejohns and Daugulis, 2008; Trigueros et al., 2010).

Some investigations have considered benzene to be a recalcitrant compound in anaerobic conditions. This behavior is generally explained due to the stabilization of the carbon-carbon bonds and the symmetric structure of the ring that make the benzene highly resistant to breaking, besides other factors (Trigueros et al., 2010).

It has also been observed that Pseudomonas aeruginosa presented a good mineralization rate, because the values of $\mathrm{Y}_{\mathrm{x} / \mathrm{s}}$, the yield of substrate transformed into biomass, were higher than the ones presented in literature for Pseudomonas putida F1. For benzene: 0.60 (Robledo-Ortíz et al., 2011), 0.75 (Abuhamed et al., 2004) and for toluene: 0.60 (Robledo-Ortíz et al., 2011), 0.58 (Abuhamed et al., 2004).

The modeling of the experimental data by the equations of Monod has been shown to be efficient, confirming that in the case of the three observed substrates their presence does not affect the cellular growth rate. This shows that the presence of the substrate does not inhibit the process. This was also proved by the lack of adjustment to the Andrews model, which through the $\mathrm{K}$ constant predicts inhibition by the substrate. These results are similar to the ones obtained in the study of the bioremediation in systems using a single substrate (Reardon et al., 2000; Bielefeldt and Stensel, 1999).

\section{CONCLUSIONS}

The kinetics of the biodegradation of monoaromatic compounds (benzene, ethylbenzene and toluene) by Pseudomonas aeruginosa suggest a promising strategy for the cleansing of monoaromatic contaminated waters, since the strain that was used did not present difficulties in totally degrading the aromatic ring.

Furthermore, the study of the kinetic parameters of the Monod model can be considered an efficient 
prediction of the kinetics of biodegradation of such compounds. A greater compatibility of Pseudomonas aeruginosa for ethylbenzene was observed, due to the low value of the saturation constant $\left(\mathrm{K}_{\mathrm{S}}\right)$. Its high mineralization rate is related to the increased reactivity of the aromatic ring caused by the presence of alkyl groups. However, a higher consumption rate was obtained for benzene since it presented the largest specific growth rate.

\section{REFERENCES}

Abuhamed, T., Bayraktar, E., Mehmetoğlu, T., and Mehmetoğlu, Ü., Kinetics model for growth of Pseudomonas putida F1 during benzene, toluene and phenol biodegradation. Process Biochemistry, 39, 983-988 (2004). https://doi.org/10.1016/S00329592(03)00210-3

Aivalioti, M., Pothoulaki, D., Papoulias, P., and Gidarakos, E., Removal of BTEX, MTBE and TAME from aqueous solutions by adsorption onto raw and thermally treated lignite. Journal of Hazardous Materials, 207, 136-146 (2012). https:// doi.org/10.1016/j.jhazmat.2011.04.084

Anneser, B., Einsiedl, F., Meckenstock, R. U., Richters, L., Wisotzky, F., and Griebler, C., High-resolution monitoring of biogeochemical gradients in a tar oil-contaminated aquifer. Applied Geochemistry, 23, 1715-1730 (2008). https://doi.org/10.1016/j. apgeochem.2008.02.003

Bailey, J. E.; Ollis, D. F. Biochemical Engineering Fundamentals. [s.l: s.n.]. v. Second

Bertin, L., Di Gioia, D., Barberio, C., Salvadori, L., Marchetti, L., and Fava, F., Biodegradation of polyethoxylated nonylphenols in packedbed biofilm reactors. Industrial \& Engineering Chemistry Research, 46, 6681-6687 (2007). https:// doi.org/10.1021/ie061663d

Bielefeldt, A. R. and Stensel, H. D. Evaluation of biodegradation kinetic testing methods and longterm variability in biokinetics for BTEX metabolism. Water Research, 33, 733-740 (1999). https://doi.org/10.1016/S0043-1354(98)00257-7

Bittkau, A.,Geyer, R., Bhatt, M. and Schlosser, D. . Enhancement of the biodegradability of aromatic groundwater contaminants. Toxicology, 205, 201-210 (2004). https://doi.org/10.1016/j. tox.2004.06.052

Bordel, S., Muñoz, R., Díaz, L. F. and Villaverde, S.. New insights on toluene biodegradation by Pseudomonas putida F1: Influence of pollutant concentration and excreted metabolites. Applied Microbiology and Biotechnology, 74, 857-866 (2007). https://doi. org/10.1007/s00253-006-0724-8

Chebbi, A., Hentati, D., Zaghden, H., Baccar, N., Rezgui, F., Chalbi, M., Sayadi, S. and Chamkha, M. . Polycyclic aromatic hydrocarbon degradation and biosurfactant production by a newly isolated Pseudomonas sp. strain from used motor oilcontaminated soil. International Biodeterioration and Biodegradation, 122, 128-140 (2017). https:// doi.org/10.1016/j.ibiod.2017.05.006

Dou, J., Liu, X. and Hu, Z. Substrate interactions during anaerobic biodegradation of BTEX by the mixed cultures under nitrate reducing conditions. Journal of Hazardous Materials, 158, 264-272 (2008). https://doi.org/10.1016/j.jhazmat.2008.01.075

Drakou, E-M., Koutinas, M, Pantelides, I. and Tsolakidou, M. I. V. Insights into the metabolic basis of the halotolerant Pseudomonas aeruginosa strain LVD-10 during toluene biodegradation. International Biodeterioration \& Biodegradation, 99, 85-94 (2015). https://doi.org/10.1016/j. ibiod.2014.10.012

El-Naas, M. H., Acio, J. A and El Telib, A. E. Aerobic biodegradation of BTEX: Progresses and Prospects. Journal of Environmental Chemical Engineering, 2, 1104-1122 (2014). https://doi.org/10.1016/j. jece.2014.04.009

Farhadian, M., Duchez, D., Vachelard, C. and Larroche, C. . Accurate quantitative determination of monoaromatic compounds for the monitoring of bioremediation processes. Bioresource Technology, 100, 173-178 (2009). https://doi.org/10.1016/j. biortech.2008.05.046

Fontes, G. C., Amaral, P. F. F. and Coelho, M. A. Z. Produção de biossurfactante por levedura. Quimica Nova, 31, 2091-2099 (2008). https://doi. org/10.1590/S0100-40422008000800033

Jo, M.-S.. Rene, E. R., Kim, S-H. and Park, H-S.. An analysis of synergistic and antagonistic behavior during BTEX removal in batch system using response surface methodology. Journal of hazardous materials, 152, 1276-1284 (2008). https://doi.org/10.1016/j.jhazmat.2007.08.002

Khodaei, K., Nassery, H. R., Asadi, M. M., Mohammadzadeh, H. and Mahmoodlu, M. G. BTEX biodegradation in contaminated groundwater using a novel strain (Pseudomonas sp. BTEX-30). International Biodeterioration \& Biodegradation, 116, 234-242 (2017). https://doi.org/10.1016/j. ibiod.2016.11.001

Lee, J. Y., Roh, J. R. and Kim, H. S. Metabolic engineering of Pseudomonas putida for the simultaneous biodegradation of benzene, toluene, and p-xylene mixture. Biotechnology and Bioengineering, 43, 1146-1152 (1994). https://doi. org/10.1002/bit. 260431120

Li, J., De Toledo, R. A. and Shim, H. Multivariate optimization for the simultaneous bioremoval of BTEX and chlorinated aliphatic hydrocarbons by Pseudomonas plecoglossicida. Journal of Hazardous Materials, 321, 238-246 (2017). https:// doi.org/10.1016/j.jhazmat.2016.09.020 
Lin, C. W., Chen, L. H. and Lay, C. Y. . Microbial communities and biodegradation in lab-scale BTEX-contaminated groundwater remediation using an oxygen-releasing reactive barrier. Bioprocess and Biosystems Engineering, 33, 383391 (2010). https://doi.org/10.1007/s00449-0090336-7

Littlejohns, J. V. and Daugulis, A. J. Kinetics and interactions of BTEX compounds during degradation by a bacterial consortium. Process Biochemistry, 43, 1068-1076 (2008). https://doi. org/10.1016/j.procbio.2008.05.010

Malhautier, L., Quijano, G., Avezac, M., Rocher, J. and Fanlo, J. L. Kinetic characterization of toluene biodegradation by Rhodococcus erythropolis: Towards a rationale for microflora enhancement in bioreactors devoted to air treatment. Chemical Engineering Journal, 247, 199-204 (2014). https:// doi.org/10.1016/j.cej.2014.02.099

Martínez, S., Cuervo-López, F. M. and Gomez, J. Toluene mineralization by denitrification in an up flow anaerobic sludge blanket (UASB) reactor. Bioresource Technology, 98, 1717-1723 (2007). https://doi.org/10.1016/j.biortech.2006.07.046

Massalha, N., Basheer, S. and Sabbah, I. Effect of adsorption and bead size of immobilized biomass on the rate of biodegradation of phenol at high concentration levels. Industrial and Engineering Chemistry Research, 46, 6820-6824 (2007). https:// doi.org/10.1021/ie070057v

Mathur, A K. and Majumder, C. B. Kinetics Modelling of the Biodegradation of Benzene, Toluene and Phenol as Single Substrate and Mixed Substrate by Using Pseudomonas putida. Chemical \& Biochemical Engineering, 24, 101-109 (2010).

Mazzeo, D. E. C., Levy, C. E., de Angelis, D. F. and Marin-Morales, M. A. BTEX biodegradation by bacteriafrom effluents of petroleum refinery. Science of the Total Environment, 408, 4334-4340 (2010). https://doi.org/10.1016/j.scitotenv.2010.07.004

Miguez, M., Nunes, P., Azeredo, N., Pedraza, S. F., Vasconcelos, M., Viana, O., Coelho, M. A. and Amaral, P. Selection of yeasts for the production of L-phenyl acetyl carbinol. Chemical Engineering Transactions, 27, 163-168 (2012).

Mirpuri, R., Jones, Wand Bryers, J. D. Toluene degradation kinetics for planktonic and biofilm-grown cells of Pseudomonas putida 54G. Biotechnology and Bioengineering, 53, 535-546 (1997). https://doi.org/10.1002/ (SICI) 1097-0290(19970320)53:6\%3C535::AIDBIT1\%3E3.0.CO;2-N

Morlett-Chávez, J. A., Ascacio-Martínez, J. A., RivasEstilla, A. M., Velázquez-Vadillo, J. F., Haskins, W. E., Barrera-Saldaña, H. A. and Acuña-Askar, K. Kinetics of BTEX biodegradation by a microbial consortium acclimatized to unleaded gasoline and bacterial strains isolated from it. International Biodeterioration and Biodegradation, 64, 581-587 (2010). https://doi.org/10.1016/j.ibiod.2010.06.010

Moussa, T. A. A.; Mohamed, M. S. and Samak, N. Production and characterization of di-rhamnolipid produced by Pseudomonas aeruginosa TMN. Brazilian Journal of Chemical Engineering, 31, 867-880 (2014). https://doi.org/10.1590/0104$6632.20140314 \mathrm{~s} 00002473$

Nagarajan, K. and Loh, K. C. Formulation of microbial cocktails for BTEX biodegradation. Biodegradation, 26, 51-63 (2014). https://doi. org/10.1007/s10532-014-9715-0

Nakhla, G. Biokinetic modeling of in situ bioremediation of BTX compounds - Impact of process variables and scaleup implications. Water Research, 37, 1296-1307 (2003). https://doi. org/10.1016/S0043-1354(02)00491-8

Nwinyi, O. C., Ajayi, O. O. and Amund, O. O. Degradation of polynuclear aromatic hydrocarbons by two strains of Pseudomonas. Braz J Microbiol, 47, 551-562 (2016). https://doi.org/10.1016/j. bjm.2016.04.026

Oberoi, A. S. and Philip, L. Variation in toxicity during the biodegradation of various heterocyclic and homocyclic aromatic hydrocarbons in single and multi-substrate systems. Ecotoxicology and Environmental Safety, 135, 337-346 (2017). https:// doi.org/10.1016/j.ecoenv.2016.10.016

Oh, Y. S., Shareefdeen, Z., Baltzis, B. C. and Bartha, $\mathrm{R}$. Interactions between benzene, toluene, and p-Xylene (BTX) during their biodegradation. Biotechnology and Bioengineering, 44, 533-538 (1994). https://doi.org/10.1002/bit.260440417

Otenio, M. H., da Silva, M. T. L., Marques, M. L. O., Roseiro, J. C. and Bidoia, E. D. Benzene, toluene and xylene biodegradation by Pseudomonas putida CCMI 852. Brazilian Journal of Microbiology, 36, 258-261 (2005). https://doi.org/10.1590/S151783822005000300010

Paixão, J. F., Nascimento, I. A., Pereira, S. A., Leite, M. B. L, Carvalho, G. C., Silveira Jr., J. S. C., Rebouças, M., Matias, G. R. A. and Rodrigues, I. L. P. Estimating the gasoline components and formulations toxicity to microalgae (Tetraselmis chuii) and oyster (Crassostrea rhizophorae) embryos: An approach to minimize environmental pollution risk. Environmental Research, 103, 365-374 (2007). https://doi.org/10.1016/j. envres.2006.06.015

Parameswarappa, S., Karigar, C. and Nagenahalli, M. Degradation of ethylbenzene by free and immobilized Pseudomonas fluorescens-CS2. Biodegradation, 19, 137-144 (2008). https://doi. org/10.1007/s10532-007-9121-y 
Phelps, C. D. and Young, L. Y. Biodegradation of BTEX under anaerobic conditions: A review. Advances in Agronomy, 70, 329-357 (2001).

Rajamanickam, R., Kaliyamoorthi, K., Ramachandran, N., Baskaran, D. and Krishnan, J. Batch biodegradation of toluene by mixed microbial consortia and its kinetics. International Biodeterioration and Biodegradation, 119, 282-288 (2017). https://doi.org/10.1016/j.ibiod.2016.11.014

Reardon, K. F., Mosteller, D. C. and Bull Rogers, J. D. Biodegradation kinetics of benzene, toluene, and phenol as single and mixed substrates for Pseudomonas putida F1. Biotechnology and bioengineering, 69, 385$400 \quad$ (2000). https://doi.org/10.1002/1097$0290(20000820) 69: 4 \% 3$ C 385 : : A I D BIT5\%3E3.0.CO;2-Q

Reusser, D. E., Istok, J. D., Beller, H. R and Field, J. A In situ transformation of deuterated toluene and xylene to benzylsuccinic acid analogues in BTEXcontaminated aquifers. Environmental Science and Technology, 36, 4127-4134 (2002). https://doi. org/10.1021/es0257366

Ridgway, H. F., Safarik, J., Phipps, D., Carl, P. and Clark, D. Identification and catabolic activity of well-derived gasoline-degrading bacteria from a contaminated aquifer. Applied and environmental microbiology, 56, 3565-3575 (1990).

Robert, M., Mercadé, M. E., Bosch, M. P., Parra, J. L., Espuny, M. J., Manresa, M. A. and Guinea, J. Effect of the carbon source on biosurfactant production by Pseudomonas aeruginosa 44T1. Biotechnol Lett, 11, 871-874 (1989). https://doi.org/10.1007/ BF01026843

Robledo-Ortíz, J. R., Ramírez-Arreola, D. E., PérezFonseca, A. A., Gómez, C., González-Reynoso, O., Ramos-Quirarte, J. and González-Núñez, R. Benzene, toluene, and o-xylene degradation by free and immobilized P. putida F1 of postconsumer agave-fiber/polymer foamed composites. International Biodeterioration and Biodegradation,
65, 539-546 (2011). https://doi.org/10.1016/j. ibiod.2010.12.011

Santa Anna, L. M., Sebastian, G. V., Menezes, E. P., Alves, T. L. M., Santos, A. S., Pereira Jr., N. and Freire, D.M.G. Production of biosurfactants from Pseudomonas aeruginosa PA1 isolated in oil environments. Brazilian Journal of Chemical Engineering, 19, 159-166 (2002). https://doi. org/10.1590/S0104-66322002000200011

Santaella, S. T., Silva Jr., F. C. G., Gadelha, D. A. C., Costa, K. O., Aguiar, R., Arthaud, I. D. B. and Leitão, R. C. Tratamento de efluentes de refinaria de petróleo em reatores com Aspergillus niger. Engenharia Sanitaria e Ambiental, 14, 139-148 (2009). https://doi.org/10.1590/S141341522009000100015

Shim, H., Hwang, B., Lee, S. S. and Kong S. H. Kinetics of BTEX biodegradation by a coculture of Pseudomonas putida and Pseudomonas fluorescens under hypoxic conditions. Biodegradation, 16, 319-327 (2005). https://doi.org/10.1007/s10532004-1842-6

Singh, P. and Tiwary, B. N. Optimization of conditions for polycyclic aromatic hydrocarbons (PAHs) degradation by Pseudomonas stutzeri P2 isolated from Chirimiri coal mines. Biocatalysis and Agricultural Biotechnology, 10, 20-29 (2017). https://doi.org/10.1016/j.bcab.2017.02.001

Trigueros, D. E., Módenes, A.N., Kroumov, A.D. and Espinoza-Quiñones, F.R., Modeling of biodegradation process of BTEX compounds: Kinetic parameters estimation by using Particle Swarm Global Optimizer. Process Biochemistry, 45, 1355-1361 (2010). https://doi.org/10.1016/j. procbio.2010.05.007

Vitolo, M., Duranti, M. A. and Pellegrim, M. B. Effect of $\mathrm{pH}$, aeration and sucrose feeding on the invertase activity of intact $\mathrm{S}$. cerevisiae cells grown in sugarcane blackstrap molasses. Journal of Industrial Microbiology, 15, 75-79 (1995). https:// doi.org/10.1007/BF01569803 